\title{
Conservação e enraizamento in vitro de infalível (Mandevilla velutina K. Schum.), uma planta medicinal do Cerrado
}

\author{
SOUZA, A.V. ${ }^{1}{ }^{*}$; BERTONI, B.W. ${ }^{2}$; FRANÇA, S.C. ${ }^{2}$; PEREIRA, A.M.S. ${ }^{2}$ \\ 'Embrapa Semiárido, CPATSA, BR 428, Km 152, Zona Rural, Caixa Postal 23, CEP:56302-970, Petrolina-Brasil \\ *ana.valeria@cpatsa.embrapa.br ${ }^{2}$ Universidade de Ribeirão Preto/UNAERP, Departamento de Biotecnologia de \\ Plantas Medicinais, Avenida Costábile Romano, 2201, CEP: 14096-900, Ribeirão Preto-Brasil, apereira@unaerp.br; \\ bbertoni@unaerp.br; sfranca@unaerp.br
}

\begin{abstract}
RESUMO: Mandevilla velutina (Apocynaceae) é uma planta medicinal endêmica do Cerrado brasileiro conhecida popularmente como infalível, utilizada pela população em tratamentos de processos inflamatórios e acidentes com serpentes. Atualmente, esta espécie encontra-se em risco de extinção, devido à coleta extrativista. Os objetivos deste trabalho foram otimizar o protocolo para o enraizamento in vitro de $M$. velutina e introduzir diferentes genótipos em banco de germoplasma in vitro, a fim de se estabelecer a conservação da espécie. Foram realizados cinco experimentos de enraizamento in vitro utilizando ANA, AIB, di e poliaminas, dithiothreitol e floroglucinol. As avaliações foram realizadas aos 30 e 60 dias quanto à porcentagem de enraizamento, número e comprimento de raiz. Para a introdução dos genótipos in vitro, foram utilizados segmentos nodais $(1 \mathrm{~cm})$ como explantes, contendo uma gema axilar ou apical, coletados de plantas mantidas em casa de vegetação, submetidos previamente à assepsia. As avaliações foram realizadas durante quatro semanas, quanto à porcentagem de contaminação dos explantes. Os resultados obtidos nas avaliações evidenciaram que a presença de compostos fenólicos no meio de cultura foi importante na promoção do enraizamento adventício in vitro de $M$. velutinae a metodologia de assepsia para a introdução de diferentes genótipos in vitro foi eficiente.
\end{abstract}

Palavras-chave: Apocynaceae, banco de germoplasma, extinção

\begin{abstract}
In vitro conservation and rooting of "infalível" (Mandevilla velutina K. Schum.), a medicinal plant of Cerrado. Mandevilla velutina (Apocynaceae) is a medicinal plant endemic to the Brazilian Cerrado, commonly known as "infalivel" and used by the population for treatments of inflammatory processes and accidents with snakes. This species is currently endangered due to extraction. The aims of this study were to optimize the protocol for in vitro rooting of $M$. velutina and to introduce different genotypes in the in vitro germplasm bank to establish the species conservation. Five experiments for in vitro rooting were conducted using NAA, IBA, di and polyamines, dithiothreitol and phloroglucinol. Evaluations were performed at 30 and 60 days as to rooting percentage, and root number and length. For the introduction of genotypes in vitro, nodal segments $(1 \mathrm{~cm})$ were used as explants; they had an axillary or apical bud and were collected from plants kept in a greenhouse after being subjected to asepsis. Evaluations were carried out for four weeks as to the percentage of explant contamination. Results showed that the presence of phenolic compounds in the culture medium was important to promote in vitro adventitious rooting in $M$. velutina and that the asepsis methodology for the introduction of in vitro of different genotypes was efficient.
\end{abstract}

Key words: Apocynaceae, germplasm bank, extinction

\section{INTRODUÇÃO}

Mandevilla velutina K. Schum. (Apocynaceae), conhecida popularmente como infalível, é uma planta medicinal endêmica do Cerrado, utilizada empiricamente na medicina popular em

tratamentos de processos inflamatórios e acidentes com serpentes, através de preparações como extratos alcoólicos ou infusões do sistema subterrâneo, composto pelo tubérculo e xilopódio

Recebido para publicação em 27/07/2009

Aceito para publicação em 09/12/2010

Rev. Bras. PI. Med., Botucatu, v.13, n.3, p.319-327, 2011. 
(Almeida et al., 1998) (Figura 1). Essas atividades foram cientificamente comprovadas nos trabalhos realizados por Calixto et al. $(1985 ; 1986 ; 1987 ; 1988)$, Bento et al. (1996) e Biondo (2003).

Sistemas de produção e cultivo de plantas medicinais ainda são incipientes e/ou inexistentes para a maioria das espécies nativas e a prevalência do processo de coleta extrativista tem exposto as espécies endêmicas das áreas prioritárias para conservação (hotspots) aos processos de erosão genética. Neste contexto, estudos e metodologias que viabilizem a produção de plantas medicinais em escala comercial são certamente recursos que podem reduzir o impacto da devastação da flora nativa.

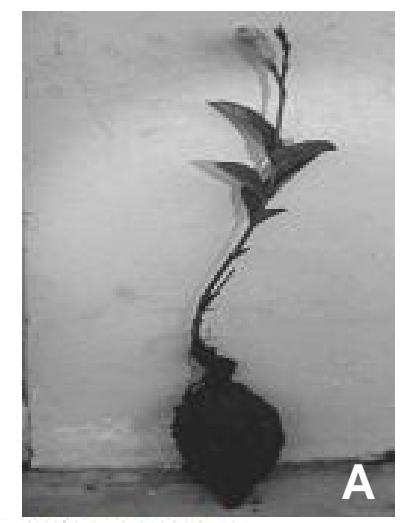

Foto: Ano M. S. Pereiro

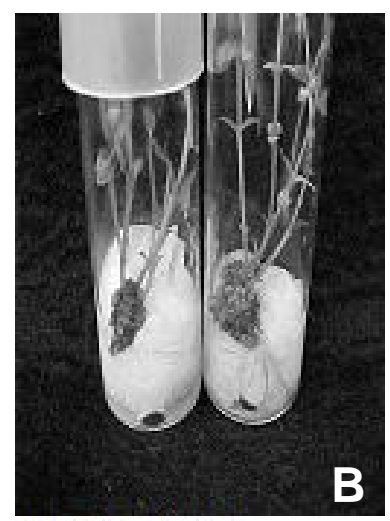

fotb: Ana V de Soura
FIGURA 1. A- Aspecto geral de Mandevilla velutina (Mart.) Woodson e B-plântulas de M. velutina enraizadas em MS/2 + $1 \mathrm{mg} \mathrm{L}^{-1}$ de ANA com tempo de permanência de 15 dias.

O protocolo de micropropagação de Mandevilla velutina e estudos de conservação em banco de germoplasma in vitro foram desenvolvidos por Biondo et al. (2007). A metodologia utilizada não apresentou resultados eficientes no enraizamento, justificando a continuidade de estudos específicos para obtenção de informações sobre a rizogênese da espécie, visando à produção de mudas in vitro.

Desse modo, os objetivos deste trabalho foram otimizar um protocolo eficiente para o enraizamento in vitro de $M$. velutina e introduzir diferentes genótipos em banco de germoplasma in vitro, a fim de se estabelecer a conservação de indivíduos remanescentes de populações naturais da espécie.

\section{MATERIAL E MÉTODO}

O trabalho foi realizado no Laboratório de Cultura de Tecidos Vegetais do Departamento de Biotecnologia e Plantas Medicinais da Universidade de Ribeirão Preto (UNAERP), em Ribeirão Preto, SP.
Os explantes utilizados para a realização dos experimentos de enraizamento foram provenientes de plântulas já estabelecidas in vitro, a partir de único genótipo, coletado no município de Araxá, MG (Altitude: 19.43.04; Longitude: 49.53.54, Altitude 949 m). Uma exsicata da espécie foi depositada no Herbário de Plantas Medicinais desta instituição (voucher HPMU oo 0013).

Em todos os experimentos, foram utilizadas brotações com $4-5 \mathrm{~cm}$ de comprimento, multiplicadas in vitro segundo protocolo estabelecido por Biondo et al. (2007), cultivadas em cubetas de vidro contendo $10 \mathrm{~mL}$ de meio de cultura. Foi utilizado o meio de cultura de Murashige \& Skoog - MS (Murashige \& Skoog, 1962) e os sais diluídos à metade (MS/2), em condição semi sólida e líquida, com pH aferido para $5,7 \pm 0,1$ antes da autoclavagem. Para os tratamentos em meio líquido, utilizaram-se papéis de filtro como suporte sólido. As cubetas $(25 \times 85 \mathrm{~mm})$ foram fechadas com tampa plástica e vedadas com parafilme, mantidas em sala de crescimento sob condições controladas de temperatura $26 \pm 1^{\circ} \mathrm{C}$, fotoperíodo de 16 horas e intensidade luminosa de $25 \mu \mathrm{mol} \mathrm{m} \mathrm{m}^{-2} \mathrm{~s}^{-1}$, fornecida por lâmpadas brancas frias do tipo fluorescente.

Todos os experimentos foram instalados em delineamento experimental inteiramente casualizado (DIC), sendo os tratamentos constituídos de 6 repetições com 5 cubetas/parcela e uma brotação por cubeta, totalizando 30 explantes/tratamento. As avaliações foram realizadas quanto à porcentagem de enraizamento, número e comprimento de raiz, aos 30 e 60 dias.

\section{Efeito do tempo de permanência dos explantes em presença de ANA e AIB}

As brotações foram cultivadas em meio de cultura MS/2 líquido controle (sem adição de regulador vegetal) ou adicionado de 1, 2, 4 e $6 \mathrm{mg} \mathrm{L}^{-1}$ de ANA (ácido naftaleno acético ou AIB (ácido indol butírico), onde permaneceram por períodos de 5, 10, 15 e 30 dias. Decorrido o período de permanência dos explantes em cada tratamento, estes foram transferidos para o mesmo meio básico, ou seja, MS/ 2 líquido, porém não adicionado de auxina, até completar 30 dias de cultivo in vitro. Os explantes que permaneceram por 30 dias em cada tratamento não foram transferidos.

Os tratamentos foram 1) controle - MS/2;2) $1 \mathrm{mg} \mathrm{L}^{-1}$ ANA ou IBA, 5 dias; 3) $1 \mathrm{mg} \mathrm{L}^{-1}$ ANA ou IBA, 10 dias; 4) $1 \mathrm{mg} \mathrm{L}^{-1}$ ANA ou IBA, 15 dias; 5) $1 \mathrm{mg} \mathrm{L}^{-1}$ ANA ou IBA, 30 dias; 6) $2 \mathrm{mg} \mathrm{L}^{-1}$ ANA ou IBA, 5 dias; 7) $2 \mathrm{mg} \mathrm{L}^{-1}$ ANA ou IBA, 10 dias; 8) $2 \mathrm{mg} \mathrm{L}^{-1}$ ANA ou IBA, 15 dias; 9) $2 \mathrm{mg} \mathrm{L}^{-1}$ ANA ou IBA, 30 dias; 10) 4 $\mathrm{mg} \mathrm{L}^{-1}$ ANA ou IBA, 5 dias; 11) $4 \mathrm{mg} \mathrm{L}^{-1}$ ANA ou IBA, 10 dias; 12) $4 \mathrm{mg} \mathrm{L}^{-1}$ ANA ou IBA, 15 dias; 13) $4 \mathrm{mg}$ $\mathrm{L}^{-1}$ ANA ou IBA, 30 dias; 14) $6 \mathrm{mg} \mathrm{L}^{-1}$ ANA ou IBA, 5 
dias; 15) $6 \mathrm{mg} \mathrm{L}^{-1}$ ANA ou IBA, 10 dias; 16) $6 \mathrm{mg} \mathrm{L}^{-1}$ ANA ou IBA, 15 dias; 17) $6 \mathrm{mg} \mathrm{L}^{-1}$ ANA ou IBA, 30 dias).

\section{Efeito de diferentes concentrações e tipos de di e poliaminas}

As brotações foram cultivadas em meios MS e MS/2 líquidos, suplementados com di ou poliaminas (espermina, espermidina, putrescina e 1,3diaminopropano), sendo o tratamento controle não adicionado de regulador vegetal.

Os tratamentos foram 1) controle - MS ou MS/ 2; 2) $1 \mathrm{mg} \mathrm{L}^{-1}$ de espermina; 3) $5 \mathrm{mg} \mathrm{L}^{-1}$ de espermina; 4) $10 \mathrm{mg} \mathrm{L}^{-1}$ de espermina; 5) $1 \mathrm{mg} \mathrm{L}^{-1}$ de espermidina; 6) $5 \mathrm{mg} \mathrm{L}^{-1}$ de espermidina; 7) $10 \mathrm{mg} \mathrm{L}^{-1}$ de espermidina; 8) $1 \mathrm{mg} \mathrm{L}^{-1}$ de putrescina; 9) $5 \mathrm{mg} \mathrm{L}^{-1}$ de putrescina; 10) $10 \mathrm{mg} \mathrm{L}^{-1}$ de putrescina; 11) $1 \mathrm{mg} \mathrm{L}^{-1}$ de $1,3-$ diaminopropano; 12) $5 \mathrm{mg} \mathrm{L}^{-1}$ de 1,3-diaminopropano; 13) $10 \mathrm{mg} \mathrm{L}^{-1}$ de 1,3-diaminopropano).

Também foram avaliados os efeitos conjuntos de $1 \mathrm{mg} \mathrm{L}^{-1}$ de ANA + 1, 5 ou $10 \mathrm{mg} \mathrm{L}^{-1}$ de putrescina sobre as brotações cultivadas em meio MS/2 líquido.

Os tratamentos foram 1) controle - MS/2 + 1 $\mathrm{mg} \mathrm{L}^{-1}$ de ANA; 2) $1 \mathrm{mg} \mathrm{L}^{-1}$ de ANA + $1 \mathrm{mg} \mathrm{L}^{-1}$ de putrescina; 3) $1 \mathrm{mg} \mathrm{L}^{-1}$ de ANA + $5 \mathrm{mg} \mathrm{L}^{-1}$ de putrescina; 4) $1 \mathrm{mg} \mathrm{L}^{-1}$ de ANA + $10 \mathrm{mg} \mathrm{L}^{-1}$ de putrescina).

\section{Efeito do Dithiothreitol}

A base das brotações selecionadas para este experimento, foram mantidas durante 1 hora em de 8 $\mathrm{mg} \mathrm{L}^{-1}$ de ágar $+0,20 \mathrm{mg} \mathrm{L}^{-1}$ de ANA e posteriormente transferidas para o meio MS $+2 \mathrm{~g} \mathrm{~L}^{-1}$ de Phytage $^{\circledR}$, suplementado com $0 ; 0,10$ e $0,25 \mathrm{mg} \mathrm{L}^{-1}$ de dithiothreitol (DTT). O tratamento sem adição do regulador vegetal foi considerado como controle.

Os tratamentos foram 1) controle - MS; 2) 0,10 $\mathrm{mg} \mathrm{L}^{-1}$ de DTT; 3) 0,25 $\mathrm{mg} \mathrm{L}^{-1}$ de DTT).

\section{Efeito do floroglucinol e ANA}

As brotações foram cultivadas em meio de cultura MS/2 líquido suplementado com 50, 100 e $200 \mathrm{mg} \mathrm{L}^{-1}$ de floroglucinol (PG) associado ou não com 1 e $2 \mathrm{mg} \mathrm{L}^{-1}$ de ANA. O tratamento sem adição do regulador vegetal foi considerado como controle.

Os tratamentos foram 1) controle - $0 \mathrm{mg} \mathrm{L}^{-1} \mathrm{de}$ floroglucinol + $0 \mathrm{mg} \mathrm{L}^{-1}$ de ANA;2) $0 \mathrm{mg} \mathrm{L}^{-1}$ de floroglucinol $+1 \mathrm{mg} \mathrm{L}^{-1}$ de ANA; 3) $0 \mathrm{mg} \mathrm{L}^{-1}$ de floroglucinol $+2 \mathrm{mg} \mathrm{L}^{-1}$ de ANA; 4) $50 \mathrm{mg} \mathrm{L}^{-1}$ de floroglucinol + $0 \mathrm{mg} \mathrm{L}^{-1}$ de ANA; 5) $50 \mathrm{mg} \mathrm{L}^{-1}$ de floroglucinol + $1 \mathrm{mg} \mathrm{L}^{-1}$ de ANA;6) $50 \mathrm{mg}$ $\mathrm{L}^{-1}$ de floroglucinol $+2 \mathrm{mg} \mathrm{L}^{-1}$ de ANA; 7) $100 \mathrm{mg} \mathrm{L}^{-1} \mathrm{de}$ floroglucinol + $0 \mathrm{mg} \mathrm{L}^{-1}$ de ANA;8) $100 \mathrm{mg} \mathrm{L}^{-1}$ de floroglucinol $+1 \mathrm{mg} \mathrm{L}^{-1}$ de ANA; 9) $100 \mathrm{mg} \mathrm{L}^{-1}$ de floroglucinol $+2 \mathrm{mg}^{-1}$ $\mathrm{L}^{-1}$ de ANA; 10) $200 \mathrm{mg} \mathrm{L}^{-1}$ de floroglucinol $+0 \mathrm{mg} \mathrm{L}^{-1} \mathrm{de}$ ANA; 11) $200 \mathrm{mg} \mathrm{L}^{-1}$ de floroglucinol + $1 \mathrm{mg} \mathrm{L}^{-1}$ deANA; 12) $200 \mathrm{mg} \mathrm{L}^{-1}$ de floroglucinol $+2 \mathrm{mg} \mathrm{L}^{-1}$ de ANA).

\section{Introdução in vitro de diferentes genótipos para a conservação em banco de germoplasma}

Para a introdução dos genótipos in vitro, foram utilizados segmentos nodais de $1 \mathrm{~cm}$ de comprimento, contendo uma gema axilar ou apical, coletados de plantas conservadas em casa de vegetação. As plantas matrizes foram borrifadas com uma solução de água destilada $+\operatorname{Cercobin~}^{\circledR}(1 \% \mathrm{p} / \mathrm{v})$ + gentamicina ${ }^{\circledR}\left(80 \mathrm{mg} \mathrm{L}^{-1}\right)$, a cada 24 horas, durante uma semana.

Os explantes coletados foram lavados com detergente comercial para a retirada de contaminantes superficiais e colocados em água corrente por duas horas. Posteriormente, foram submergidos em solução de $\operatorname{Cercobin}^{\circledR}(0,2 \%$ p/v) por $24 \mathrm{~h}$ sob agitação de $80 \mathrm{rpm}$. Após este tratamento, os explantes foram transferidos para solução de hipoclorito de sódio $(0,5 \%$ $\mathrm{p} / \mathrm{v}$ ) por 20 min e transferidos para meio de cultura MS semi-sólido, sem lavagem prévia em água.

Para este experimento, foram utilizadas cubetas de vidro contendo $10 \mathrm{~mL}$ de meio, solidificado com $2 \mathrm{~g} \mathrm{~L}^{-1}$ de Phytage ${ }^{\circledR}$ e pH ajustado para 5,7+/0,1 antes da autoclavagem. As cubetas de vidro (25 x $85 \mathrm{~mm}$ ) foram tampadas com tampa plástica e vedadas com parafilme e colocadas em sala de crescimento sob condições controladas de temperatura $26 \pm 1^{\circ} \mathrm{C}$, fotoperíodo de 16 horas e intensidade luminosa de $25 \mu \mathrm{mol} \mathrm{m}{ }^{-2} \mathrm{~s}^{-1}$, fornecida por lâmpadas fluorescentes brancas frias. Foram realizadas avaliações semanais quanto à porcentagem de contaminação dos explantes, durante quatro semanas.

\section{RESULTADO E DISCUSSÃO}

$A$ adição de ambas as auxinas nas concentrações avaliadas neste trabalho não foi eficiente para promover a formação de raízes in vitro das plântulas de $M$. velutina, resultando em enraizamento das brotações inferiores a $10 \%$ nas duas datas de avaliação, sendo o AIB menos efetivo em comparação ao ANA (Figuras 2 e 3). Também não foram observadas diferenças estatísticas entre os tratamentos quanto ao número e comprimento de raízes, sendo o valor médio de 1 raiz/brotação, com $1,0 \mathrm{~cm}$ de comprimento.

Quanto às aminas, alguns autores ressaltam que existe correlação entre o conteúdo endógeno de di e poliaminas e o desenvolvimento de raízes (Sankhla \& Upadhyaya, 1988; Couée et al., 2004). Contudo, para a espécie $M$. velutina, estas substâncias também não foram efetivas na promoção do enraizamento satisfatório das brotações sob condição in vitro (Figura 4), assim como a associação de diferentes concentrações de putrescina com $1 \mathrm{mg}$ $\mathrm{L}^{-1}$ de ANA (Figura 5). Os resultados de porcentagem de enraizamento e número e comprimento médio de raízes obtidos neste experimento foram semelhantes aos obtidos nos experimentos com auxinas. 


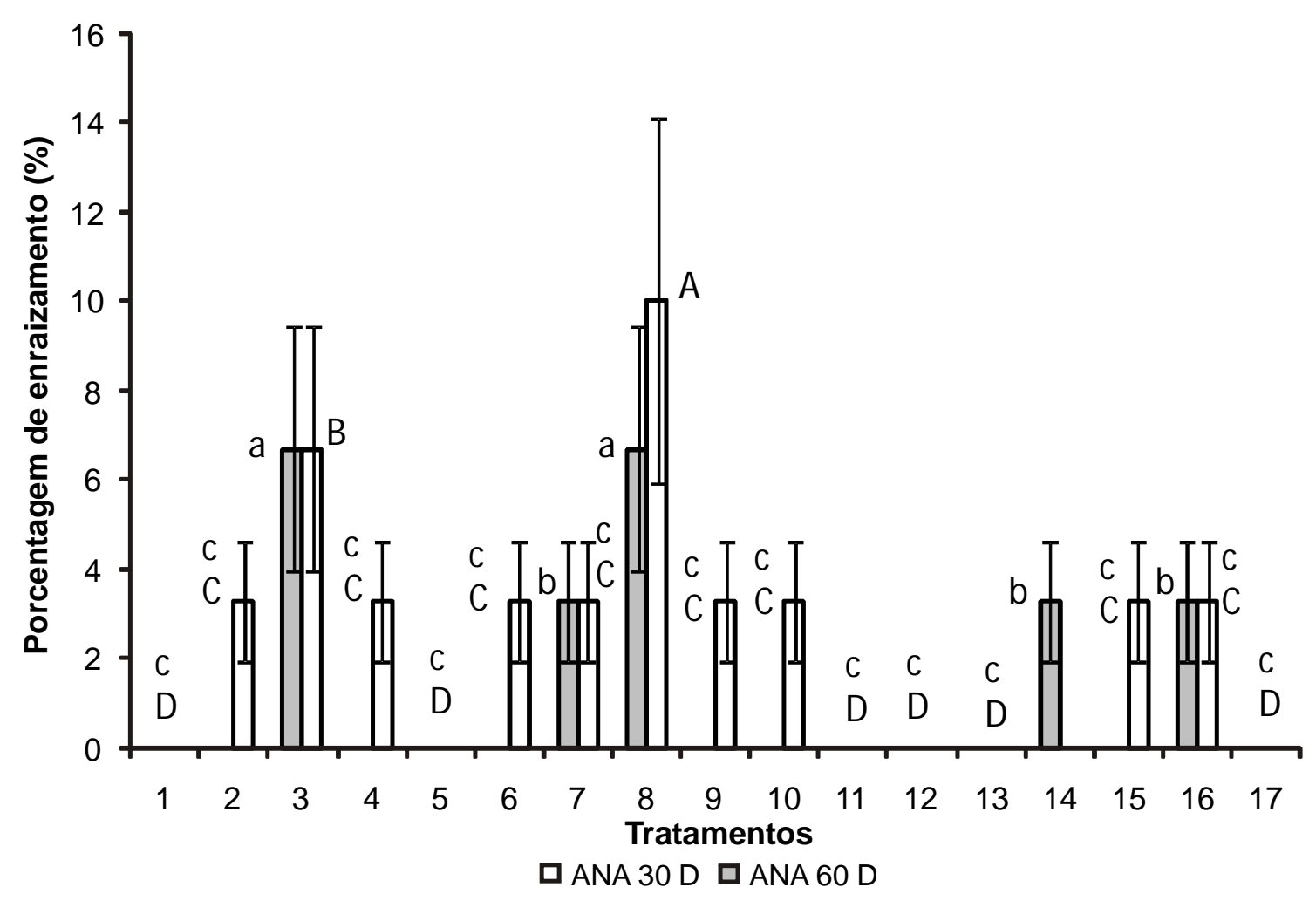

FIGURA 2. Porcentagem de enraizamento de brotações de Mandevilla velutina em função de diferentes tempos de permanência em diferentes concentrações de ANA aos 30 e 60 dias. Médias seguidas da mesma letra, não diferem entre si pelo teste de Tukey (?5\%). Letras minúsculas e maiúsculas correspondem aos valores obtidos aos 30 e 60 dias de avaliação.

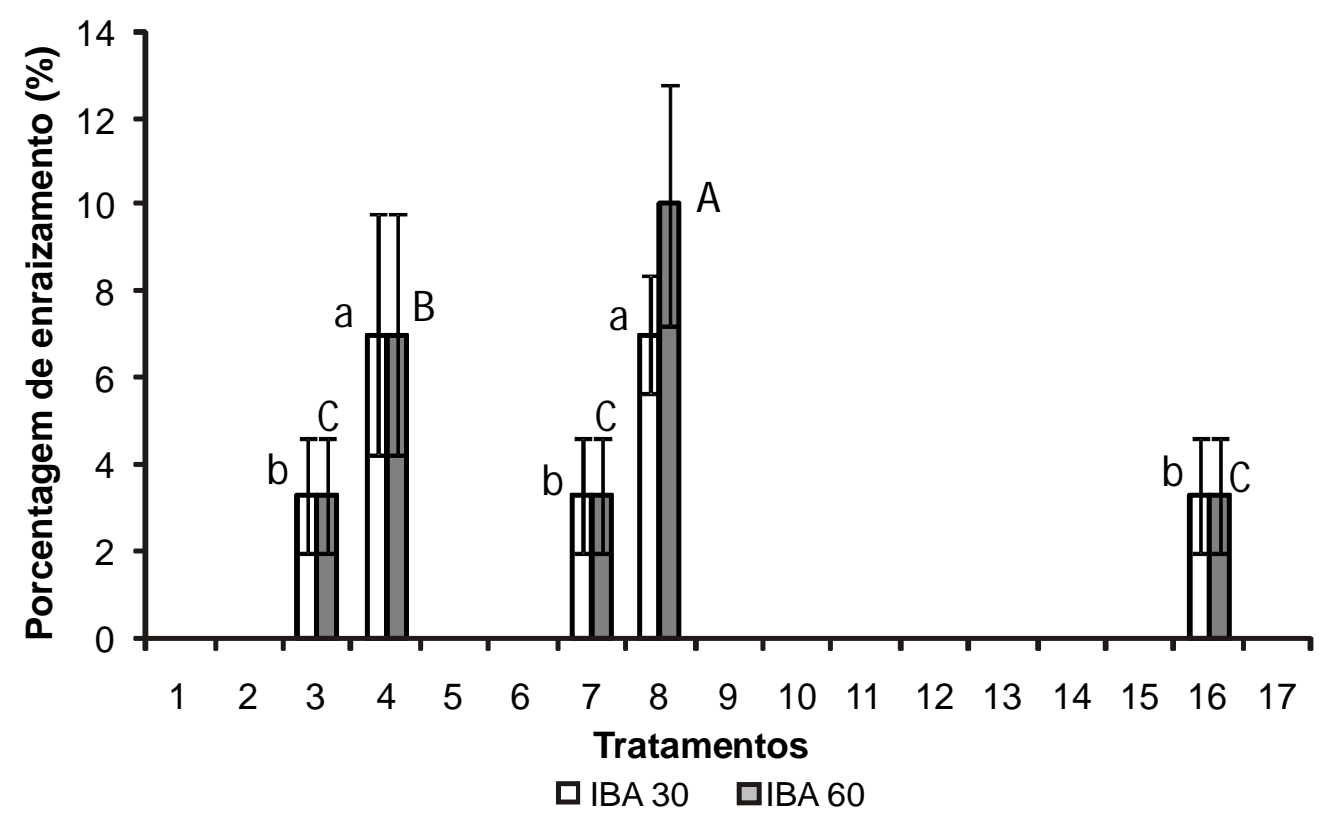

FIGURA 3. Porcentagem de enraizamento de brotações de Mandevilla velutina em função de diferentes tempos de permanência em diferentes concentrações de AIB aos 30 e 60 dias. Médias seguidas da mesma letra, não diferem entre si pelo teste de Tukey (a5\%). Letras minúsculas e maiúsculas correspondem aos valores obtidos aos 30 e 60 dias de avaliação. 


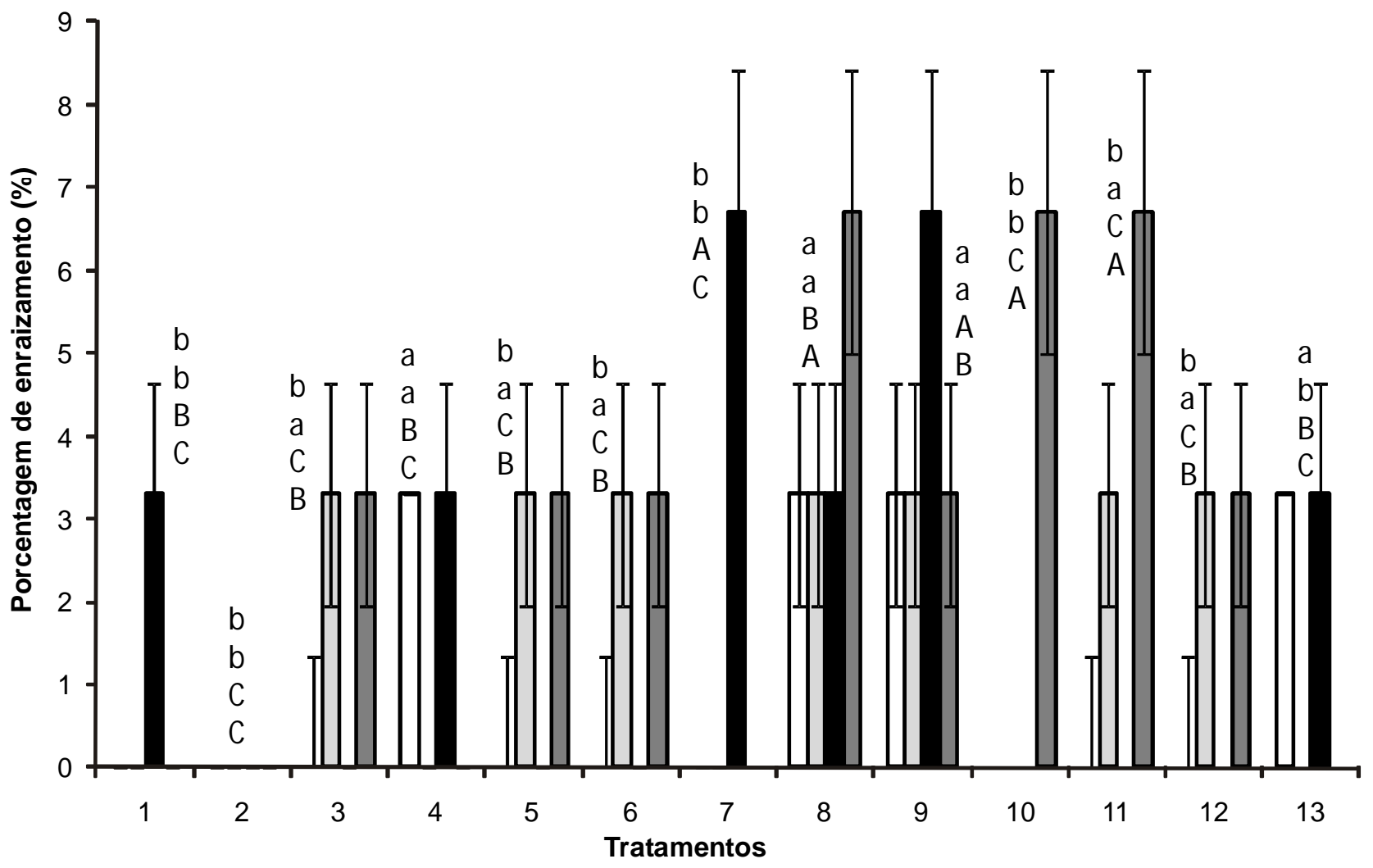

口MS 30 口MS2 30 MS 60 aMS2 60

FIGURA 4. Porcentagem de enraizamento de brotações de Mandevilla velutina em função de diferentes concentrações e tipos de diaminas e poliaminas em meio MS e MS/2, aos 30 e 60 dias. Médias seguidas da mesma letra, não diferem entre si pelo teste de Tukey (a5\%). Letras minúsculas e maiúsculas correspondem aos valores obtidos aos 30 e 60 dias de avaliação.

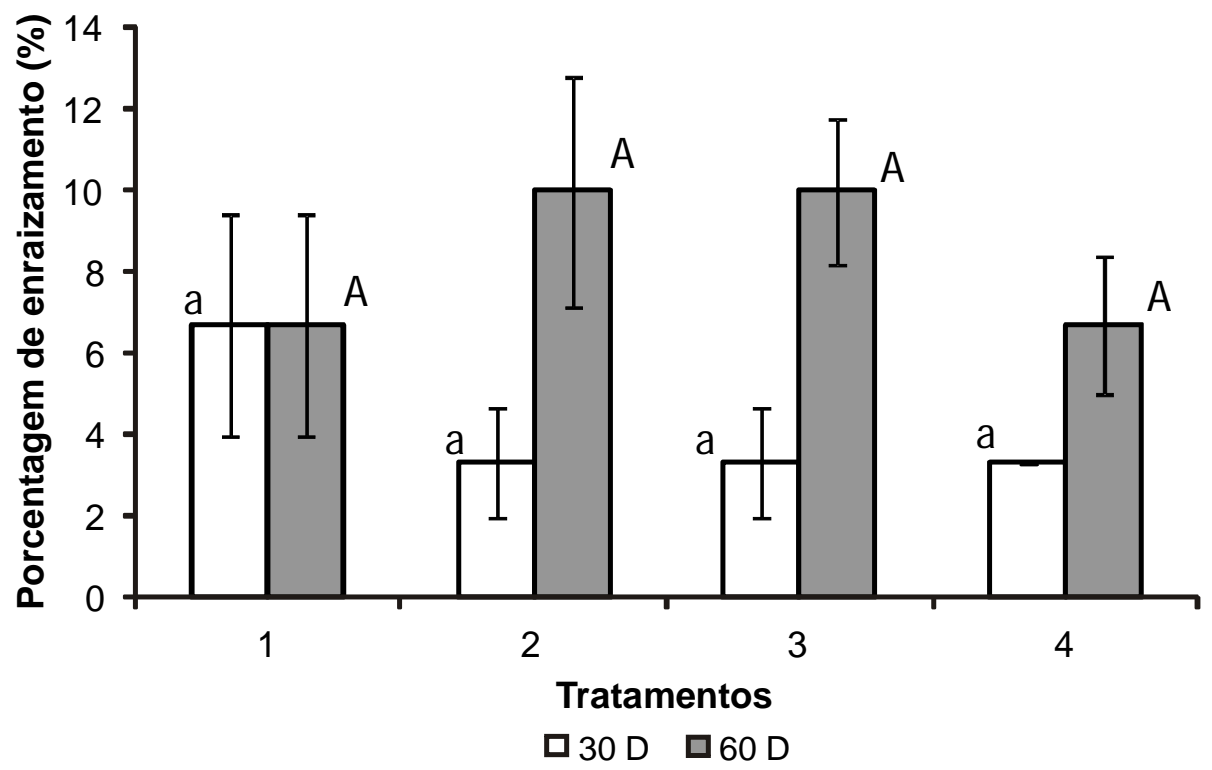

FIGURA 5. Porcentagem de enraizamento de brotações de Mandevilla velutina em função de diferentes concentrações de putrescina associada a $1 \mathrm{mg} \mathrm{L}^{-1}$ de ANA, aos 30 e 60 dias. Médias seguidas da mesma letra, não diferem entre si pelo teste de Tukey (a5\%). Letras minúsculas e maiúsculas correspondem aos valores obtidos aos 30 e 60 dias de avaliação, respectivamente. 
Souza \& Pereira (2007) em trabalho de revisão sobre enraizamento de plantas cultivadas in vitro citaram vários estudos que confirmam o efeito benéfico das auxinas no enraizamento adventício. A ação positiva das auxinas durante esta etapa é conhecida de longa data e ocorre durante as fases de indução e iniciação das raízes (em períodos de duas, três e/ou quatro semanas), aproximadamente, quando há a conjugação com a auxina endógena e a formação do primórdio radicular (Gaspar \& Hofinger, 1988; Assis \& Teixeira, 1998; Grattapaglia \& Machado, 1998; Ford et al., 2002).

Em espécies consideradas difíceis de enraizar, após o tratamento com as auxinas sintéticas, ocorre aumento na concentração de AIA endógeno e posteriormente decréscimo, antes da formação das raízes. Nesse caso, não ocorre a conjugação com a auxina exógena para a formação do primórdio radicular (Gaspar \& Hofinger, 1988; Ford et al., 2002; Aloufa, 2003), o que pode ter ocorrido em M. velutina. Tendo em vista que a concentração de reguladores utilizados não foi efetiva para promover o enraizamento adventício in vitro de $M$. velutina, esta pode ser considerada uma espécie difícil de enraizar.

Mesmo que a conjugação entre a auxinaANA e a diamina putrescina não tenha sido efetiva para promover o enraizamento in vitrode $M$. velutina, estudos realizados por Neves et al. (2002) mostraram que as poliaminas favoreceram o enraizamento na presença e/ou ausência de auxinas em brotos e plântulas micropropagadas de Vitis vinifera. Segundo os autores, as poliaminas devem estar presentes nos tecidos radiculares e favorecer o enraizamento, conjugandose com o AIA endógeno.
Contudo, as plântulas de $M$. velutina não devem possuir níveis de poliaminas nos tecidos radiculares, bem como, níveis suficientes de auxina endógena que possam favorecer o enraizamento, haja vista os resultados obtidos nos experimentos descritos anteriormente. Como a ação positiva das diaminas e poliaminas sobre a indução de raízes adventícias está relacionada ao nível de auxina endógeno, a conjugação poliaminas-auxinas certamente não ocorreu para esta espécie.

Todavia, é necessária a realização de estudos bioquímicos para que se possa estabelecer de modo preciso a relação entre a presença e/ou nível de auxina e poliamina endógena e o seu efeito no enraizamento in vitro de $M$. velutina, confirmando esta inferência.

Vários estudos têm evidenciado a relação entre o decréscimo nos níveis endógenos das diaminas e poliaminas e a inibição do crescimento das raízes, enquanto um aumento nos teores destas substâncias tem sido observado durante o crescimento dos tecidos e a organogênese (Sankhla \& Upadhyaya, 1988; Couée et al., 2004; Tang \& Newton, 2004). No entanto, as respostas quanto ao efeito positivo ou negativo destas substâncias sobre a indução de raízes é significativamente variável entre as espécies (Couée et al., 2004).

Os resultados deste estudo com $M$. velutina, evidenciam a necessidade da realização de experimentos bioquímicos específicos durante as diferentes fases de enraizamento, para a quantificação de auxinas, di e poliaminas nos tecidos radiculares e a identificação de seu envolvimento na indução de raízes adventícias para esta espécie.

Por outro lado, a permanência das brotações

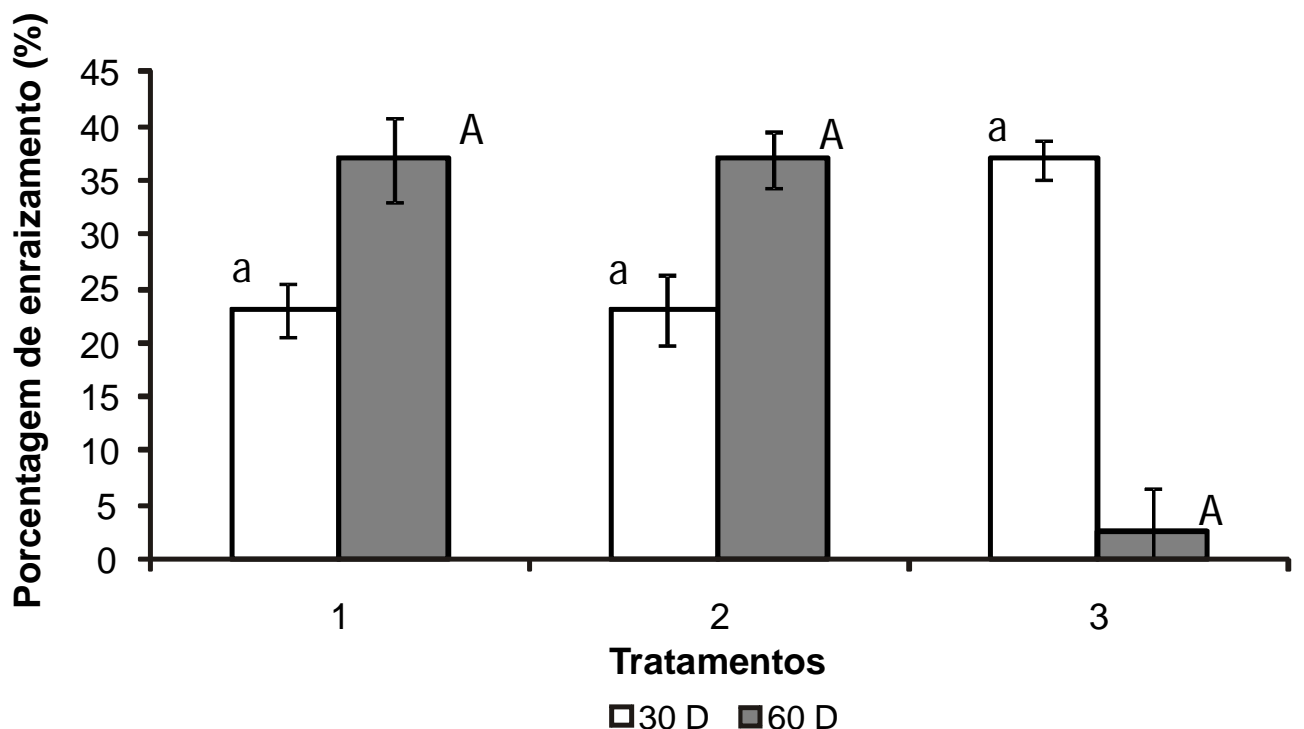

FIGURA 6. Porcentagem de enraizamento de brotações de Mandevilla velutina em função de diferentes concentrações de dithiothreitol (DTT), aos 30 e 60 dias. Médias seguidas da mesma letra, não diferem entre si pelo teste de Tukey (a5\%). Letras minúsculas e maiúsculas correspondem aos valores obtidos aos 30 e 60 dias de avaliação, respectivamente. 
de $M$. velutina por 60 dias, em meio de cultura suplementado com $0,25 \mathrm{mg} \mathrm{L}^{-1}$ de DTT promoveu o enraizamento em $47 \%$ das brotações (Figura 6). Mesmo que este valor não tenha ultrapassado $50 \%$, o resultado foi melhor quando comparado àqueles obtidos nos estudos realizados por Biondo et al. (2007), com a mesma espécie, quando obteve $33 \%$ de brotações enraizadas. Mas também não houve diferença estatística significativa para número e comprimento de raizes. Resultados semelhantes e satisfatórios de enraizamento in vitro em meio contendo DTT, também foram obtidos com as espécies Mandevilla sanderi, Malus domesticae Daphne odora (Auderset et al., 1997).

O floroglucinol teve efeito benéfico sobre a indução de raízes adventícias in vitro nas brotações de $M$. velutina em todas as concentrações testadas. A presença de diferentes concentrações de PG no meio de cultura, sozinho ou em combinação com a auxina ANA, promoveu o enraizamento em algumas brotações (Figura 7). Contudo, verificou-se que, também não houve diferença estatística significativa entre os tratamentos para as variáveis número e comprimento de raiz.

Segundo McCown (1988), o efeito de compostos fenólicos como PG é sinérgico com auxinas, porém a resposta é dependente do genótipo e de pré condições da cultura, podendo também ter efeito inibitório. No entanto, os resultados obtidos são diversos entre as espécies, inibindo ou favorecendo o enraizamento adventício. Os fenóis induzem a formação de raízes adventícias, na ausência de auxinas exógenas, por meio do aumento o nível de auxina endógena (Lima, 1998), o que pode ter ocorrido nas brotações de $M$. velutina cultivadas somente na presença do PG. Mas neste caso, também é necessária a realização de análises bioquímicas, a fim de verificar a relação deste fenol com a auxina endógena, nesta espécie.

Resultados semelhantes aos obtidos com $M$. velutina foram relatados nos trabalhos realizados por Al-Maarri et al. (1994) e por Berardi et al. (1993), com as espécies Pyrus communis cv Williams e Pyrus callerana, respectivamente. Para a espécie Pyrus pyrifolia, a adição de $P G$ ao meio de enraizamento aumentou a porcentagem de brotos enraizados e a sobrevivência das plântulas na fase de aclimatização (Bhojwani et al., 1984).

As respostas obtidas com $M$. velutina mostraram que algumas brotações enraizaram somente na presença de $P G$ ou quando este foi associado ao ANA. Mesmo que a porcentagem de enraizamento tenha sido baixa, esses resultados são interessantes, porque em experimentos futuros, podese testar outras concentrações de PG, bem como a conjugação de $P G$ + ANA + AIB sob condições variadas.

\section{Introdução in vitro de diferentes genótipos para a conservação em banco de germoplasma}

O protocolo de assepsia realizado nos explantes de $M$. velutina para a introdução dos genótipos in vitro foi estabelecido com sucesso. De acordo com as avaliações realizadas, verificou-se que não houve contaminação por fungos ou bactérias nos segmentos nodais transferidos para condições in vitro e a regeneração das plântulas ocorreu normalmente, possibilitando a introdução de 10 genótipos e a produção de 24 plântulas por genótipo (Tabela 1), mantidos no banco de germoplasma "Cerrado in vitro" da Universidade de Ribeirão Preto, segundo protocolo estabelecido por Biondo et al. (2007).

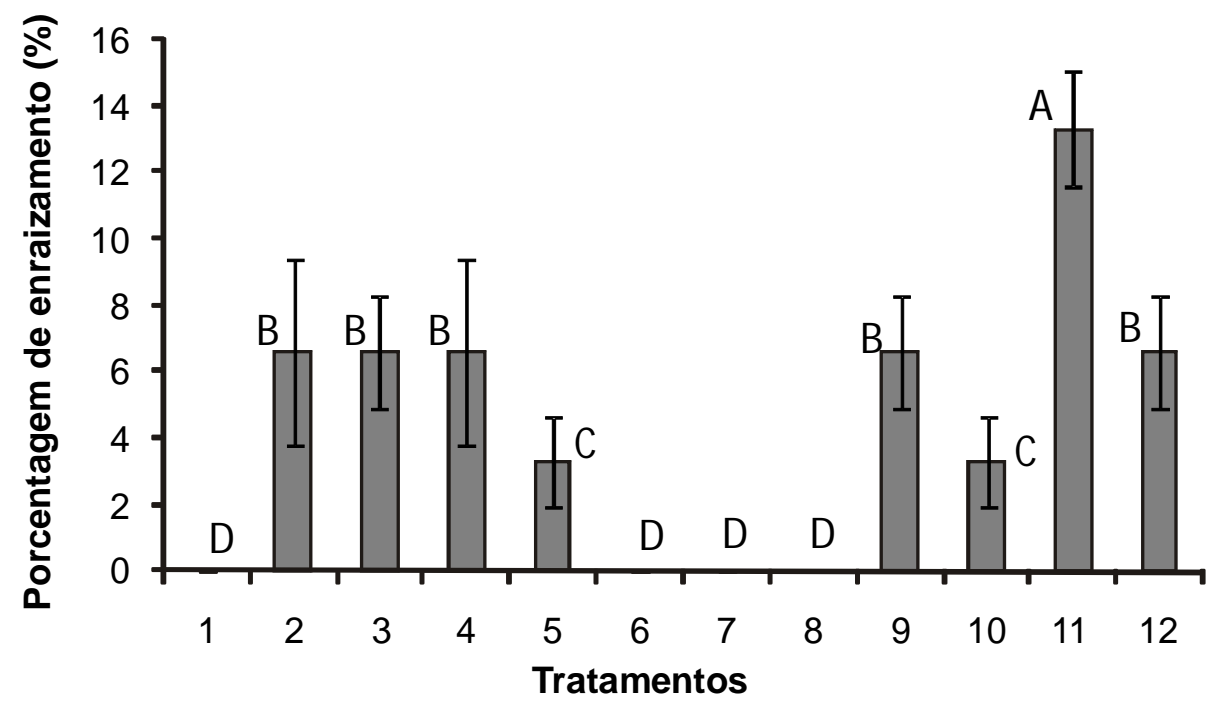

FIGURA 7. Porcentagem de enraizamento de brotações de Mandevilla velutina em função da interação floroglucinol x ANA, aos 60 dias. Médias seguidas da mesma letra, não diferem entre si pelo teste de Tukey (a5\%). Letras maiúsculas correspondem aos valores obtidos aos 60 dias de avaliação. 
TABELA1. Genótipos de Mandevilla velutina introduzidos in vitro para conservação em banco de germoplasma.

\begin{tabular}{cccccc}
\hline Genótipo & $\begin{array}{c}\text { Local } \\
\text { Cidade - UF }\end{array}$ & & Dados GPS & $\begin{array}{c}\text { № indivíduos banco } \\
\text { germoplasma in vitro }\end{array}$ \\
\cline { 3 - 5 } & & Latitude & Longitude & Altitude & \\
\cline { 3 - 5 } Co & São Carlos/SP & $21.53 .49,0$ & $47.54 .15,1$ & $823 \mathrm{~m}$ & 24 \\
SC2 & São Carlos/SP & $21.53 .53,1$ & $47.54 .13,8$ & $850 \mathrm{~m}$ & 24 \\
SC12 & São Carlos/SP & $21.53 .50,3$ & $47.54 .22,2$ & $820 \mathrm{~m}$ & 24 \\
Araxá & Araxá/MG & $19.35 .26,5$ & $47.06 .41,0$ & $976 \mathrm{~m}$ & 24 \\
HP2 & Araxá/MG & 19.43 .04 & 49.53 .54 & $949 \mathrm{~m}$ & 24 \\
I6 & Itatinga/SP & $23.14 .54,9$ & $48.40 .35,0$ & $676 \mathrm{~m}$ & 24 \\
UB 1 & Uberaba - Araxá/MG & $19.42 .05,8$ & $47.41 .19,8$ & $1004 \mathrm{~m}$ & 24 \\
Sa1 & Araxá - Sacramento/MG & $19.42 .19,5$ & $47.06 .52,7$ & $1104 \mathrm{~m}$ & 24 \\
M5 & Alto Araguaia/MT & $17.12 .15,2$ & $53.21 .26,8$ & $759 \mathrm{~m}$ & 24 \\
M1 & Alto Araguaia/MT & $17.12 .15,2$ & $53.21 .26,8$ & $759 \mathrm{~m}$ & 24 \\
\hline
\end{tabular}

A pulverização das plantas de $M$. velutina em casa de vegetação com um coquetel de fungicida e antibiótico favoreceu a diminuição dos contaminantes superficiais como fungos e bactérias e facilitou o estabelecimento do protocolo de assepsia. As concentrações dos agentes químicos utilizados e o tempo de submersão dos explantes à estas substâncias, pode ser indicada como a condição ótima para a introdução in vitro desta espécie.

\section{CONCLUSÃO}

A presença de compostos fenólicos no meio de cultura foi importante para promover o enraizamento adventício in vitro de $M$. velutina, o que possibilita a realização de experimentos futuros quando se poderá conjugar ou não estas substâncias com as auxinas sintéticas.

A metodologia de assepsia utilizada para introdução in vitro de diferentes genótipos de $M$. velutina foi eficiente e pode ser indicada para outras espécies do Cerrado, quando o interesse for o estabelecimento de protocolos de micropropagação e conservação in vitro a partir de segmentos nodais advindos de plantas matrizes mantidas em casa de vegetação.

\section{AGRADECIMENTO}

Às agências de fomento a pesquisa CAPES e Fapesp, pelo apoio financeiro.

\section{REFERÊNCIA}

AL-MAARRI, K.; ARNAUD, Y.; MIGINIAC, E. Micropropagation of Pyrus communis cultivar 'Pease Crassane' seedlings and cultivar 'Williams': factors affecting root formation in vitro and ex vitro. Scientia Horticulturae, v.58, p.207-14, 1994.

ALMEIDA, S.P. et al. Cerrado: espécies vegetais úteis. Planaltina: EMBRAPA-CPAC, 1998. 464p.

ALOUFA, M.A.I. Enraizamento in vitro de plantas lenhosas: dificuldades e soluções. In: CONGRESSO BRASILEIRO DE FLORICULTURA E PLANTAS ORNAMENTAIS, 14., CONGRESSO BRASILEIRO DE CULTURA DE TECIDOS DE PLANTAS, 1., 2003, Lavras. Palestras... Universidade Federal de Lavras: UFLA, 2003, p.23-36.

ASSIS, T.F.; TEIXEIRA, S.L. Enraizamento de plantas lenhosas. In: TORRES, A.C.; CALDAS, L.S.; BUSO, J.A. (Eds.). Cultura de tecidos e transformação genética de plantas. Brasília: Embrapa-SPI / Embrapa-CNPH, 1998. v.1, p. 261-96.

AUDERSERT, G. et al. Stimulation of root formation in difficult-to-toot woody cuttings by dithiothreitol. International Journal of Plant Sciences, v.158, n.2, p.1325, 1997.

BENTO, E.S. et al. The structure of velutinol $A$ is (15R, 16R, 20S)-14,16: 15,20: 16,21-triepoxy-15,16-seco14beta, 17alfa-pregn-5-ene-3beta, 15-diol. A combined quantitative Overhauser effect and molecular modelling study. Journal of Chemical Society Perkin Transactions, v.2, n.7, p.1359-66, 1996.

BERARDI, G.; INFANTE, R.; NERI, D. Micropropagation of Pyrus calleryana Dcn. from seedlings. Scientia Horticulturae, v.53, p.157-65, 1993.

BIONDO, R. Avaliação da variabilidade genética, das propriedades antiofídicas e conservação in vitro de Mandevilla velutina (Mart) Woodson. 2003.119p. Dissertação (Mestrado em Biotecnologia) - Universidade de Ribeirão Preto, Ribeirão Preto.

BIONDO, R. et al. Micropropagation, seed propagation and germoplasma bank on Mandevilla velutina (Mart.) Woodson. Scientia Agricola, v.64, n.3, p.263-8, 2007. BHOJWANI, S.S.; MULLINS, K.; COHEN, D. In vitro propagation of Pyrus pyrifolia. Scientia Horticulturae, v.23, p.247-54, 1984.

CALIXTO, J.B.; NICOLAU, M.; YUNES, R.A. A selective antagonist of bradykinin action from a crude extract of 
Mandevilla velutina. Parte II. Effect on isolated rat uterine amooth-muscle. Brazilian Journal of Medical and Biological Research, v.18, n.5-6, p.729-31, 1985.

CALIXTO, J.B. et al. Antiedematogenic actions of a hidroalcoholic crude water-alcohol extract of Mandevilla velutina. Brazilian Journal of Medical and Biological Research, v.19, p.4-5, 1986.

CALIXTO, J.B. et al. Kinin antagonistic effect of compounds from Mandevilla velutina in the rat isolated uterus. Brazilian Journal Pharmacology, v.91, n.1, p.199204, 1987.

CALIXTO, J.B. et al. The competitive antagonist activity of compounds form Mandevilla velutina on Kinin-induced contractions of rat uterus and guinea-pig ileum in vitro. Brazilian Journal Pharmacology, v.94, n.4, p.1133-42, 1988.

COUÉE, I. et al. Involvement of polyamines in root development. Plant Cell, Tissue and Organ Culture, v.76, p.1-10, 2004.

FORD, Y.Y. et al. Adventitious rooting: examining the role of auxin in easy and a difficult-to-root plant. Plant Growth Regulation, v.36, n.2, p.149-59, 2002.

GASPAR, T.; HOFINGER, M. Auxin metabolism during adventitious rooting. In: DAVIS, T.D.; HAISSIG, B.E.; SANKHLA, N. Adventitious root formation in cuttings. Oregon, 1988. v.2, p.117-31.

GRATTAPAGLIA, D.; MACHADO, M.A. Micropropagação. In: TORRES, A.C.; CALDAS, L.S.; BUSO, J.A. Cultura de tecidos e transformação genética de plantas. Brasília:
Embrapa-SPI / Embrapa-CNPH, 1998. v.1, p.43-76. LIMA, C.C.M. Uso de aditivos e cofatores na rizogênese de plântulas de Eucalyptus grandis Hill. in vitro. 1998. 99p. Dissertação (Mestrado em Ciências florestais) Escola Superior de Agricultura "Luiz de Queiroz", Universidade de São Paulo, Piracicaba.

McCOWN, B.H. Adventitious rooting of tissue cultured plants. In: DAVIS, T.D.; HAISSIG, B.E.; SANKHLA, N. Adventitious root formation in cuttings. Oregon, 1988. v.2, p.289-302.

MURASHIGE, T.; SKOOG, F. A revised medium for rapid growth and bioassays with tobaco tissue cultures. Physiologia Plantarum, v.1, p.437-96, 1962.

NEVES, C. et al. Involvement of free and conjugated polyamines and free amino acids inthe adventitious rooting of micropropagated cork oak and gravepine shoots. Plant Physiology and Biochemistry, v.40, p.1071-80, 2002.

SANKHLA, A.; UPADHYAYA, A. Polyamines and adventitious root formation. In: DAVIS, T.D.; HAISSIG, B.E.; SANKHLA, N. Adventitious root formation in cuttings. Oregon, 1988. v.2, p.289-302.

SOUZA, A.V.; PEREIRA, A.M.S. Enraizamento de plantas cultivadas in vitro. Revista Brasileira de Plantas Medicinais, v.9, n.4, p.103-17, 2007.

TANG, W.; NEWTON, R.J. Increase of polyfhenol oxidase and decrease of polyamines correlate with tissue browning in Virginia pine (Pinus virginiana Mill.). Plant Science, v.167, n.3, p.621-8, 2004. 